Review Article

\title{
Contribution of Zinc and Zinc Transporters in the Pathogenesis of Inflammatory Bowel Diseases
}

\author{
Wakana Ohashi $\mathbb{D}^{1}$ and Toshiyuki Fukada $\mathbb{D}^{2}$ \\ ${ }^{1}$ Department of Molecular and Medical Pharmacology, Graduate School of Medicine and Pharmaceutical Sciences for Research, \\ University of Toyama, Toyama, Japan \\ ${ }^{2}$ Molecular and Cellular Physiology, Faculty of Pharmaceutical Sciences, Tokushima Bunri University, Yamashiro, Tokushima, Japan
}

Correspondence should be addressed to Wakana Ohashi; wohashi@med.u-toyama.ac.jp

and Toshiyuki Fukada; fukada@ph.bunri-u.ac.jp

Received 7 November 2018; Accepted 29 January 2019; Published 10 March 2019

Academic Editor: Patrice Petit

Copyright (C) 2019 Wakana Ohashi and Toshiyuki Fukada. This is an open access article distributed under the Creative Commons Attribution License, which permits unrestricted use, distribution, and reproduction in any medium, provided the original work is properly cited.

\begin{abstract}
Intestinal epithelial cells cover the surface of the intestinal tract. The cells are important for preserving the integrity of the mucosal barriers to protect the host from luminal antigens and pathogens. The mucosal barriers are maintained by the continuous and rapid self-renewal of intestinal epithelial cells. Defects in the self-renewal of these cells are associated with gastrointestinal diseases, including inflammatory bowel diseases and diarrhea. Zinc is an essential trace element for living organisms, and zinc deficiency is closely linked to the impaired mucosal integrity. Recent evidence has shown that zinc transporters contribute to the barrier function of intestinal epithelial cells. In this review, we describe the recent advances in understanding the role of zinc and zinc transporters in the barrier function and homeostasis of intestinal epithelial cells.
\end{abstract}

\section{Introduction}

The gastrointestinal tract absorbs nutrients from digested foods and protects against luminal antigens and invading pathogens, including commensal bacteria and food. For this protective function, the intestines have developed a robust system of physical, chemical, and biological mucosal barriers. Defects in the mucosal barriers lead to the translocation of luminal antigens into the host, which induces host immune and inflammatory responses. These responses increase the susceptibility to various gastrointestinal diseases. Maintenance of the mucosal barrier system is therefore a critical issue in intestinal health [1]. The intestinal epithelial cells generate and maintain the mucosal barriers by continuous renewal [2]. Any impairment in the renewal cycle perturbs the mucosal barriers. Maintenance of the intestinal epithelial homeostasis is essential for preserving mucosal barrier functions.

Zinc is an essential trace element for all living organisms and is involved in a variety of important biological processes.
It is a nonredox transition metal that serves as a catalytic cofactor and has structural functions in numerous proteins. Bioinformatics analyses have revealed that approximately $10 \%$ and $6 \%$ of the genes in the genomes of humans and bacteria, respectively, encode products with zinc-binding potential [3-5]. The functions of zinc-binding proteins are highly divergent and include transcription factors, DNA synthase, ubiquitin ligase, receptors, and kinases [3]. Zinc acts as a signaling molecule, such as second messengers, to mediate signaling pathways [6-9]. Zinc deficiency dysregulates cellular functions. Excess zinc is also toxic to cells. Thus, the level and distribution of zinc must be tightly fine-tuned. Zinc transporters regulate the distribution of zinc by controlling zinc influx and efflux via organelle membranes, thereby contributing to the maintenance of zinc homeostasis $[10,11]$. Zinc transporters consist of two families: solute carrier (SLC) 39A and SLC30. The SLC39A/Zrt- and Irt-related protein (ZIP) family has 14 members and functions to transport zinc from the extracellular/organelle region into the cytosol. The SCL30A/Zn transporter ( $\mathrm{ZnT}$ ) is composed of 10 
members and participates in exporting zinc from the cytosol. By regulating the flux of zinc, zinc transporters are involved in the regulation of various zinc-mediated biological functions. The physiological and pathological functions of zinc transporters have been explored through genetic approaches [10-12].

Several lines of evidence suggest that zinc deficiency causes diarrhea and mucosal barrier dysfunction, while zinc supplementation improves symptoms [13]. Thus, in the intestine, zinc is essential to maintain intestinal homeostasis and regulate intestinal disorder. In this review, we focus on the roles of zinc and zinc transporters in intestinal epithelial homeostasis and disorder.

\section{Intestinal Epithelial Cell: A Critical Player in the Mucosal Barriers}

The small intestine is composed of villi that protrude into the lumen and crypts that penetrate the mucosa. In contrast, the large intestines have no protruding villi, consisting only of crypts that allow water absorption. The surface of the intestinal mucosa is covered by a monolayer of intestinal epithelial cells. These cells consist of differentiated and undifferentiated cells [14]. Differentiated epithelial cells include absorptive enterocytes, mucin-producing goblet cells, and Paneth cells, which secrete antibacterial factors and constitute a niche for intestinal stem cells [15-19]. All intestinal epithelial linages are derived from intestinal stem cells. Intestinal stem cells that feature leucine-rich repeatcontaining G-protein-coupled receptor 5 (Lgr5) as a marker protein constantly self-renew and produce daughter cells that are designated transit-amplifying (TA) cells [20]. TA cells undergo vigorous proliferation to increase the number of the cells, which differentiate into specialized epithelial lineages. Most differentiated epithelial cells migrate from the crypts to the tip of the villi as they differentiate. Intestinal epithelial cells reaching the tips of the villi undergo apoptosis. The renewal of intestinal epithelial cells takes 3-5 days in mice or 1 week in humans $[21,22]$.

Intestinal stem cells are cells that are capable of both self-renewal and multipotency. The number of the intestinal stem cells is dynamically regulated. In the steady state, the stem cell number is maintained at a certain level. During development or tissue repair, the stem cells actively selfrenew, contributing to increased tissue size or repair [23]. Crypt base columnar (CBC) cells are distributed between Paneth cells at the crypt base and express Lgr5. Lgr5 is the target gene of canonical Wingless-Int (Wnt) signaling, wherein Lgr5 functions as the receptor and mediates R-spondin signaling, thus potentiating Wnt signaling [24-26]. The Lgr5 ${ }^{+}$CBC cells represent actively cycling stem

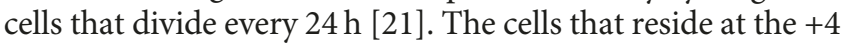
position immediately above the Paneth cells in the crypts also represent a stem cell population. The +4 cells dominantly express Hopx and display the slow cycling and DNA label-retention characteristics of quiescent stem cells. Recent studies suggest that they are a reverse stem cell population that can be rapidly recruited to maintain epithelial homeostasis following injury $[27,28]$. Indeed, when $\operatorname{Lgr} 5^{+}$stem cells are lost, $\mathrm{Hopx}^{+}$quiescent stem cells express Lgr5, leading to their active self-renewal, thereby compensating for the loss of Lgr $5^{+}$stem cells. Furthermore, Hopx ${ }^{+}$quiescent stem cells and $\operatorname{Lgr} 5^{+}$active cells can compensate for one another when the other cell type is depleted [27].

Goblet cells are a secretory lineage that has an important role in the generation of the mucus layer by secreting O-glycosylated mucin proteins [15]. Mucus gel layers on the intestinal surface present a physicochemical barrier that prevents the invasion of microorganisms [29]. The mucus layer is composed of an outer layer colonized by microorganisms, and a sterile dense inner layer firmly attached to the epithelial surface that contains antibacterial molecules [29]. The mucus layer also contains immunoglobulin A (IgA) produced by $\mathrm{B}$ cells in the lamina propria. Secreted IgA in the lumen has a role in neutralizing invading pathogens, antigen presentation to microfold cells ( $M$ cells) on the follicular-associated epithelium surface, and disturbance of the attachment of microorganisms on the epithelial surface [30]. In addition to the barrier function, the mucus layer also serves as a nutrient source for intestinal microbes [31]. Polymerized MUC2 in the inner layer is proteolytically degraded to generate the outer layer that is colonized by microorganisms. The mucus layer is highly glycosylated and can be utilized as an energy source by intestinal microbes during dietary fiber-depleted conditions. This leads to the erosion of the mucus barrier, which induces intestinal inflammation [31], implying that the nutritional state could influence the strength of the mucus barrier.

Paneth cells secrete various antibacterial molecules, such as $\alpha$-defensins and RegIII- $\gamma$, and participate in innate immunity in the gastrointestinal tract $[32,33] . \alpha$-Defensins are cationic peptides consisting of 18-45 amino acid residues. Upon binding to the cellular surface of a microorganism, $\alpha$-defensins form cationic pores in the membrane. Disruption of the cell membrane integrity leads to an efflux of nutrients or ions, which kills the bacteria [34]. The secretion of antimicrobial peptides depends on bacterial sensing [32]. Paneth cells express pathogen recognition receptors (PRRs), including Toll-like receptors and nucleotide oligomerization domain 2 (NOD2). Therefore, Paneth cells play a role in innate immunity by sensing bacteria and bacterial antigens. Paneth cells also store a large amount of zinc in their granules $[35,36]$. Bacteria or bacterial components bind to PRRs, inducing the secretion of antibacterial molecules and zinc from Paneth cells [32, 33, 37, 38]. Additionally, Paneth cells also secrete maintenance factors, such as epidermal growth factors (EGFs) and Wnt3a, to form a niche for intestinal stem cells [39]. Thus, Paneth cells contribute to intestinal stem cell homeostasis and innate immunity by serving as biological barriers.

Cell junctions, which include the tight and adherens junction, firmly link intestinal epithelial cells, thereby forming a physical barrier that inhibits microbial invasion by the paracellular pathway. Pathogen-associated molecular pattern signaling regulates physical barrier functions. TLR2 signaling can enhance intestinal integrity by preserving the expression of zonula occludins-1 (ZO-1), a critical component of the tight junction in the intestinal epithelial 
cells [40]. The NOD-like receptor family is a component of inflammasomes. In the intestines, molecules that include adenosine triphosphate (ATP), DNA, and RNA are secreted from injured cells. These secreted molecules act as danger signals that result in the activation of inflammasomes. It has been reported that NLRP3- or NLRP6-dependent secretion of interleukin- (IL-) $1 \beta$ and IL-18 contributes to the maintenance of intestinal epithelial homeostasis by promoting the maturation and regeneration of intestinal epithelial cells $[41,42]$. Thus, the innate immune signaling regulates both the physiological and biological barrier formations.

\section{Intestinal Epithelial Cells during Intestinal Inflammation}

Emerging evidence suggests that impaired integrity of the mucosal barrier is associated with the pathogenesis of intestinal inflammation $[43,44]$. Tight junctions restrict the translocation of luminal materials into the host, thereby protecting the host from luminal antigens and pathogens. Defects in tight junctions (e.g., increased apoptosis of intestinal epithelial cells) cause focal leakages that allow water and small molecules to enter the mucosa, thus inducing a mucosal immunological response [45]. The dysfunction of cell junctions causes intestinal inflammation. Inflammatory bowel diseases (IBDs), which include ulcerative colitis (UC) and Crohn's disease (CD), involve the chronic inflammation of the gastrointestinal tract characterized by epithelial barrier dysfunctions and alterations in immune regulation. IBD patients display increased paracellular permeability with tight junction abnormalities. Moreover, decreased expressions of junctional molecules, such as occludins and claudins, have been found in patients with IBDs [46-48]. Mice lacking claudin-7, an important component of tight junctions, have enhanced paracellular organic solute flux and develop spontaneous colitis [49].

Dysfunctions of Paneth cells have been observed with various intestinal inflammatory diseases. Reduced secretion of $\alpha$-defensin and other antimicrobial peptides was described in patients with $\mathrm{CD}$ [50]. In particular, $\alpha$-defensin 5 is downregulated in these patients [51-53]. This might be related to the alteration in epigenetic modification status. The $\alpha$-defensin 5 gene in patients with CD is highly methylated compared to the gene in healthy individuals [54]. Thus, epigenetic programming might be a causal factor in the pathogenesis of CD. NOD2 acts as an intracellular bacterial sensor by recognizing muramyl dipeptide (MDP), a structural component of bacteria. Mice deficient in NOD2 display decreased production of $\alpha$-defensin in Paneth cells and are very susceptible to Listeria infections [37]. Adaptor protein(AP-) $1 \mathrm{~B}$ is a polarized sorting factor that mediates the polarized secretion of proteins by regulating intracellular protein sorting. The loss of AP-1B function results in the reduced expression of antimicrobial proteins and impaired IgA secretion, leading to the development of spontaneous chronic colitis by hypoepithelial barrier function [55]. Decreased expressions of AP-1M2 have also been observed in patients with $\mathrm{CD}[55]$.
Defective mucin is also involved in the pathogenesis of IBDs. Mucin2 (MUC2) expression is decreased in patients with IBDs [56]. Lack of MUC2 reportedly leads to the development of spontaneous colitis characterized by mucosal thickening and superficial erosions [57]. The same authors reported that mice lacking MUC2 showed severe damage against dextran sodium sulfate- (DSS-) induced experimental colitis.

The pathogenesis of IBDs is multifactorial and includes environmental and genetic factors. Regarding the genetic factors, recent genome-wide association studies (GWAS) have identified multiple genes associated with the risk of IBD [58-61]. Variations in the genes related to epithelial barrier functions, such as NOD2 and FUT2, have been identified as genes associated with the pathogenesis of IBDs [59, 61]. Homeostasis of intestinal epithelial cells is maintained through continuous self-renewal, including rapid proliferation, differentiation, and apoptosis. Wnt/ $\beta$-catenin and Notch signaling have essential roles for the intestinal epithelial turnover [62]. Defects in these processes also lead to the impairment of barrier functions and IBD pathogenesis. GWAS have identified Wnt signaling-related genes $\mathrm{T}$ cell factor 4 (TCF4) and lipoprotein receptor-related protein 6 (LRP6) as associated with the risk for IBD [63]. The functional variant in LRP6 has been associated with early-onset ileal CD [64]. Furthermore, a recent study reported specific changes in the DNA methylation status in the intestinal epithelial cells that were associated with the development of IBD, suggesting that intestinal epithelial cell functions are epigenetically regulated along with the disease development [65].

\section{Zinc in Intestinal Diseases}

Zinc is an essential trace element in living organisms, including mammalians, bacteria, and plants. It has been estimated that approximately $10 \%$ of the human genome encode zinc-binding proteins [3]. Consequently, zinc-binding proteins constitute a large proportion of the total proteome [4]. The functions of these zinc-binding proteins are very diverse. Dysregulation of zinc homeostasis is associated with the pathogenesis of gastrointestinal diseases [13].

Zinc deficiency induces to diarrhea $[13,66,67]$. Reduced serum zinc levels or decreased zinc levels in the colorectal mucosa have been found in patients with persistent diarrhea. Zinc supplementation is effective in the prevention or improvement of diarrhea [67-69]. The World Health Organization has recommended zinc supplementation for the treatment of diarrhea as it reduces the duration and severity of symptoms associated with diarrhea and prevents subsequent episodes [70]. Zinc deficiency can also lead to an increased risk of gastrointestinal infectious diseases [71]. In pathogenic bacterial infections, the tissue zinc level was altered in the inflamed intestine. In a mouse model of Salmonella infection, the level of zinc was reduced in the inflamed gut [72]. Zinc also has a beneficial effect on infectious diseases like shigellosis. Malabsorption of nitrogen and the abnormal loss of mucus and transmucosal protein have been reported in patients with shigellosis. 

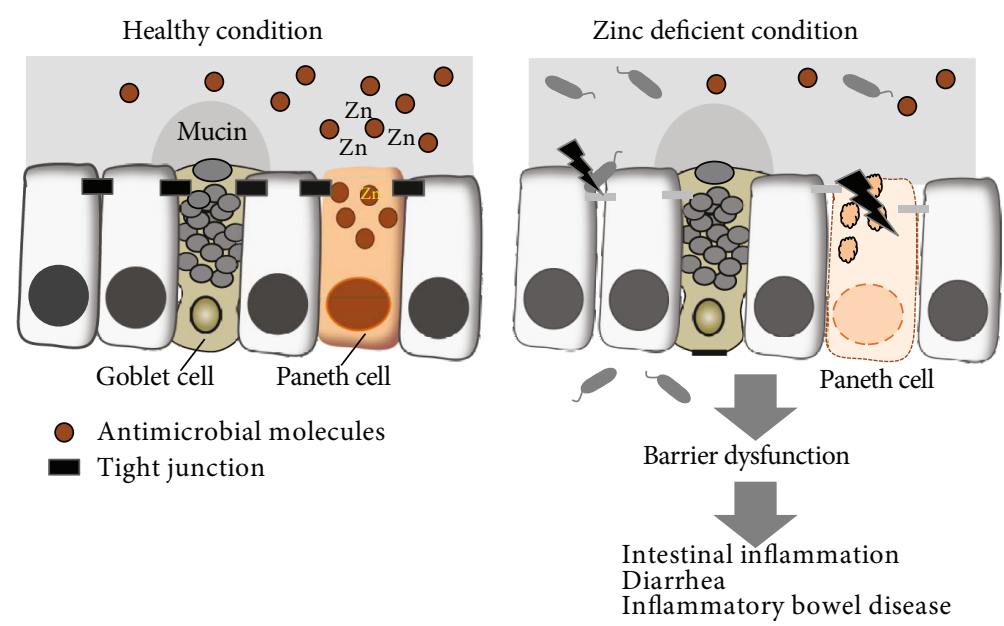

Figure 1: Zinc preserves mucosal barrier functions. In healthy conditions, mucosal barriers, including tight junctions, the mucus layer, and antimicrobial molecules, protect the host from luminal antigens/pathogens. In contrast, in zinc-deficient conditions, mucosal barriers are impaired. Thus, luminal contents can access the mucosal surface and translocate across the epithelial cells, leading to inflammation and intestinal diseases.

Zinc supplementation improves intestinal barrier function, intestinal permeability, nitrogen absorption, and symptoms and also increases immune responses [73-76].

Serum zinc levels in patients with CD are reduced compared to levels in healthy individuals $[13,77]$. The absorption of zinc in patients with IBD is also lower compared to healthy controls. Although the relationship between low serum zinc levels and $\mathrm{CD}$ development is somewhat controversial, zinc supplementation appears to have beneficial effects on disease outcomes [78, 79]. A prospective study showed that the supplementation of zinc led to improved outcomes for patients with $\mathrm{CD}$ [80]. A cohort study of female IBD patients suggested that zinc intake can reduce the risk for CD [81]. The influence of zinc deficiency on colitis has also been examined in animal studies. For example, zinc deficiency exacerbates the severity of experimental colitis in rats $[82,83]$. The severity of colitis has been correlated with serum zinc levels in mice [83]. Consistent with these reports, zinc treatment improved the severity of experimental colitis in mice [84-87]. The molecules that mediate the beneficial effect of zinc in colitis have been explored. GPR39 is a specific zinc receptor expressed on the plasma membrane [88]. Upon sensing extracellular zinc, GPR39 activates downstream signal pathways to regulate cellular functions, including proliferation, differentiation, and survival [89]. GPR39 sensing of extracellular zinc appears to affect the severity of colitis. Mice lacking GPR39 showed increased mortality after the induction of experimental colitis [90].

\section{Zinc and Zinc Transporters in Intestinal Epithelial Cells}

5.1. Mucosal Barriers. Disruption of the physical barrier formed by intestinal epithelial cells is associated with gastrointestinal diseases [45, 91]. Increased apoptosis of the intestinal epithelial cells causes weakened epithelial barrier tightness and induces focal leaks. Focal leaks lead to increased intestinal permeability and leak fluxes, followed by the activation of immunological responses in the mucosa. Decreased barriers lead to leaky gut properties. Emerging evidence has implicated zinc in the maintenance of the mucosal barriers (Figure 1) [85, 92]. Zinc deficiency leads to reduced expressions of occludin and ZO-1 proteins, resulting in decreased tight junctions in Caco-2 cells [93]. Depletion of zinc induces occludin-3 proteolysis and decreased claudin-3 transcription [94]. In contrast, in mice with bacterial infections, zinc supplementation protects the mice from intestinal dysfunction and intestinal leakage induced by bacterial toxins [95]. Zinc supplementation also enhances tight junctions in Caco-2 cells, characterized by an increase in transepithelial electrical resistance (TEER) and induced expressions of claudin-2, claudin-7, and ZO-1 proteins $[96,97]$. Furthermore, zinc facilitates tight junction formation via GPR39 by preserving occludin and ZO-1 expressions in Caco2 and HT29 cells (Figure 2(a)) [98]. Zinc also activates the mammalian target of rapamycin pathway via GPR39 in HT29 cells [98]. Thus, the zinc-GPR39 axis seems to have a regulatory role in tight junction strength between intestinal epithelial cells. The ZIP14 zinc transporter is expressed on plasma membranes and mediates zinc influx into the cytosol, thereby regulating cellular signaling (Figure 2(a)). Mice lacking ZIP14 display increased intestinal permeability associated with altered expressions of tight junction proteins of claudin-1 and claudin-2 [99]. Thus, zinc transporter-mediated zinc signaling may affect the intestinal barrier functions. As described above, Paneth cells contain a large amount of zinc in their granules $[35,36]$. Considering that Paneth cells are susceptible to zinc deficiency, zinc seems to contribute to the establishment of a biological barrier, since Paneth cells have a critical role in the production of antimicrobial molecules.

5.2. Intestinal Immunity. Intestinal macrophages are abundant in the small and large intestines. In particular, they are found in close proximity to the intestinal epithelial cells [100]. The major functions of intestinal macrophages are 

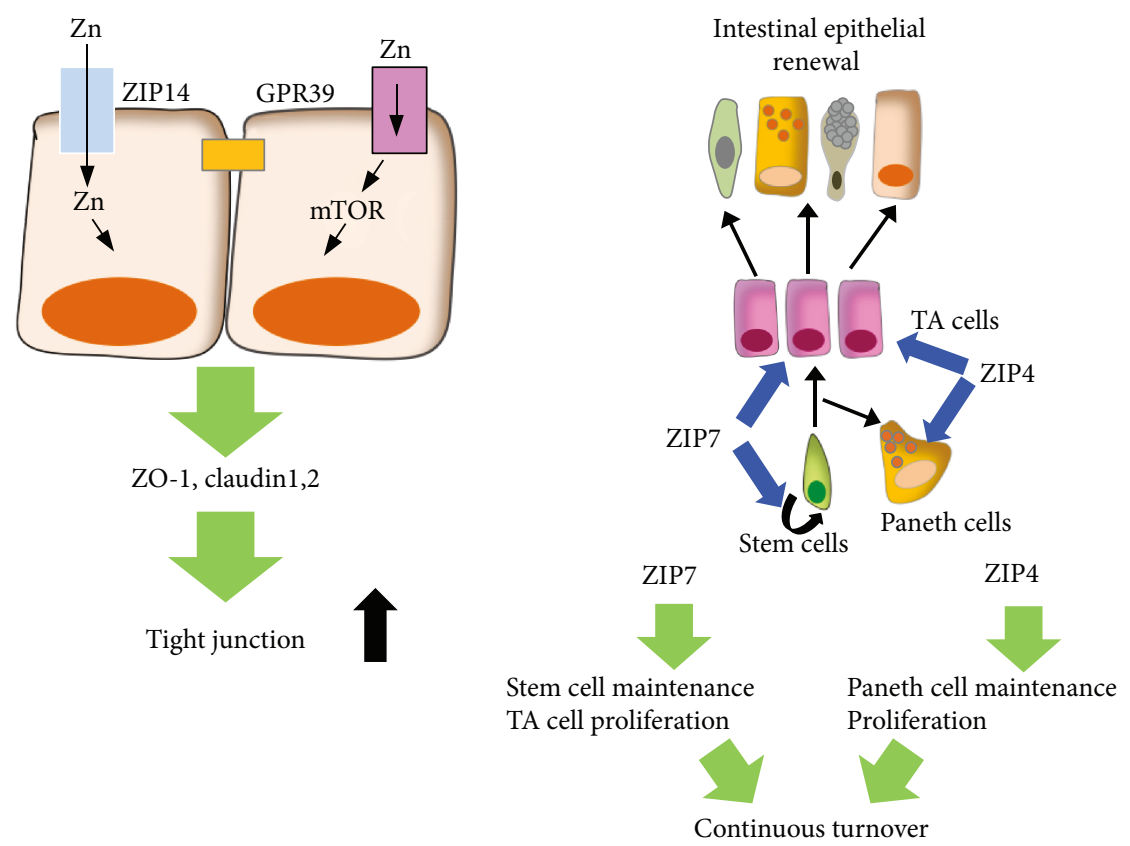

(a)

(b)

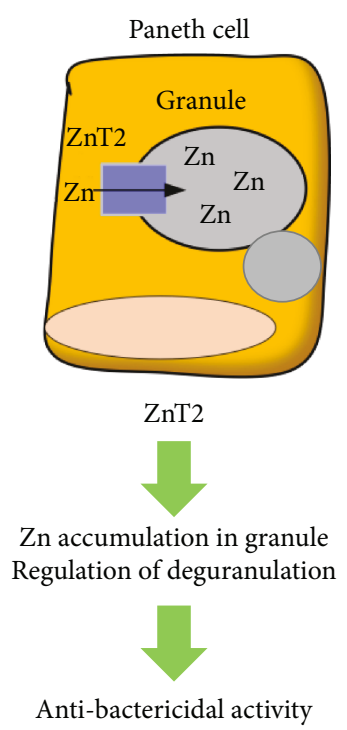

(c)

FIGURE 2: Zinc in intestinal epithelial cells ZIP14 and GPR39 mediates the establishment of the physical barrier through tight junctions (a). ZIP7 and ZIP4 contribute to the maintenance of intestinal homeostasis by securing continuous epithelial turnover (b). ZnT2 facilitates zinc accumulation into the secretory granule, contributing to the antimicrobial function of Paneth cells.

sensing, uptake, and clearance of microorganisms invading across the epithelial barrier. Intestinal macrophages thus play an important role in the maintenance of gut homeostasis by contributing to barrier functions. Compared to peritoneal macrophages, intestinal macrophages are highly bactericidal and show increased expressions of metallothionein 1 (MT-1) associated with increased intracellular zinc level [101]. The increased zinc level in intestinal macrophages is missing in mice treated with antibiotics. Furthermore, NOD2 ligand MDPs can induce the upregulation of MT-1 and intracellular zinc levels in intestinal macrophages [101]. Thus, zinc may have a role in regulating the bactericidal potential of intestinal macrophages, thereby mediating a part of symbiotic relationship in the intestine. Dysbiosis has been proposed as a key feature of IBD [102]. There is experimental evidence of the involvement of zinc in the microflora community, whereby excess dietary zinc alters the gut microbiota [103]. Mice fed with an excess zinc diet showed decreased microbial diversity without affecting the bacterial burden. Recently, the association of a variant of zinc transporter ZIP8 with CD was reported [104]. The healthy ZIP8 variant carrier showed altered gut microflora partially overlapping with those in patients with $\mathrm{CD}$. Thus, disturbed zinc homeostasis might be associated with dysbiosis. 
5.3. Intestinal Zinc Absorption. ZIP4 plays an important role in zinc absorption from the small intestine [105]. ZIP4 localized on the apical membrane of intestinal epithelial cells controls the incorporation of luminal zinc into the host by multiple mechanisms [105-108]. The dysfunction of ZIP4-mediated zinc absorption due to ZIP4 gene mutations causes acrodermatitis enteropathica [109-111]. ZnT1 is detected at the basolateral membrane [112]. Expression of $\mathrm{ZnT1}$ is affected by dietary zinc supplementation. With zinc supplementation, ZnT1 expression is increased in the rat intestine $[112,113]$. Since ZnT1 belongs to the SLC30A/ZnT family that mediates zinc export from the cytosol into the extracellular or intracellular compartment, ZnT1 may also mediate zinc transport from the intestinal epithelial cells to the extracellular region (i.e., the blood stream). Thus, ZIP4 and $\mathrm{ZnT1}$ appear to have important roles in the intake of zinc. ZIP5 is localized on the basolateral side of the intestinal epithelial cells and participates in zinc excretion $[106,114]$. Mice lacking ZIP5 in intestinal epithelial cells accumulate zinc in the pancreas [115]. Interestingly, expressions of ZIP4 and ZIP5 are oppositely regulated by zinc. In the zinc-deficient condition, expression of ZIP4 is increased and ZIP5 expression is decreased [108]. On the contrary, the ZIP4 level is suppressed in the zinc-adequate condition, whereas ZIP5 expression is induced [108]. Additionally, $\mathrm{ZnT5B}$, which is a splicing variant of $\mathrm{ZnT5}$, has been reported to be localized to the apical membrane of the epithelium in the small intestine [116]. Since ZnT5B is capable of bidirectional transport of zinc [116, 117], ZnT5B appears to mediate zinc influx as well as efflux from the epithelial cells. Thus, zinc absorption and excretion are likely determined by the regulation of specific zinc transporters.

5.4. Intestinal Epithelial Homeostasis. Zinc deficiency leads to alterations in the integrity and function of the intestinal epithelial cells, demonstrating a role for zinc in intestinal epithelial homeostasis [118]. However, exactly how zinc carries out this role is unclear. Recent studies have indicated that zinc transporters contribute to the maintenance of intestinal epithelial homeostasis by regulating cellular function.

ZIP4 has a role in the regulation of intestinal epithelial function (Figure 2(b)). Mice lacking ZIP4 in the intestinal epithelial cells have decreased expressions of Sox9, a marker for Paneth cells; induction of mucin, a marker of goblet cells; and loss of zinc in Paneth cells. These findings suggest that ZIP4-mediated zinc incorporation is necessary for the differentiation and maintenance of Paneth cells [119]. Moreover, ZIP4 also contributes to the proliferation of intestinal epithelial cells [119]. Mice lacking ZIP4 display disrupted villus integrity. Thus, ZIP4 appears to be important in preserving intestinal epithelial architecture.

$\mathrm{ZnT2}$ is the zinc transporter expressed on the secretory granules in Paneth cells [120]. ZnT2 promotes the accumulation of zinc in granules in the Paneth cells [120]. Furthermore, ZnT2 regulates the secretion of antimicrobial molecules in Paneth cells (Figure 2(c)) [120]. The authors described degranulated Paneth cells in ZnT2-deficient mice and the unchanged overall structure of the villi-crypt axis. The findings indicate that $\mathrm{ZnT} 2$ are not involved in the continuous self-renewal of intestinal epithelial cells, but rather in Paneth cell function [120].

ZIP7 is an endoplasmic reticulum- (ER-) localized zinc transporter that is highly expressed in the crypts, rather than the villi, in the intestine [121]. In the crypts, intestinal stem cells, TA cells, and Paneth cells express ZIP7. A recent study described the essential role for ZIP7 in the maintenance of intestinal epithelial homeostasis (Figure 2(b)) [121]. The authors described that deletion of ZIP7 in the intestinal epithelial cells in mice caused an acute loss of proliferating cells by apoptosis, with the disappearance of intestinal stem cells [121]. Furthermore, ZIP7 deficiency elevated ER stress in TA cells and stem cells [121]. The villus-crypt structure was completely disrupted in the ZIP7-deficient intestine. Additionally, degenerated Paneth cells were found in the ZIP7-deficient crypts, suggesting the essential role of ZIP7 in Paneth cell maintenance [121]. These findings indicate that ZIP7 is indispensable for the rapid turnover of intestinal epithelial cells by preserving the survival of intestinal stem cells, proliferation of crypts cells, and resolving ER stress. Notch, EGF, and Wnt signaling critically contributes to the maintenance of intestinal stem cells as well as proliferation of intestinal epithelial cells [122]. Recent studies have implicated ZIP7 in these signaling events in other cell types. ZIP7 is involved in the activation of extracellular signalregulated kinases, which is major downstream molecule of EGF in breast cancer cells [123]. ZIP7 participates in the regulation of the trafficking of Notch in T cell acute lymphoblastic leukemia cells [124]. Accordingly, the treatment of ZIP7-binding compound led to the alteration of the zinc level in the ER, disturbed Notch trafficking, and disrupted apoptosis via an ER stress mechanism. Although the relationship between ZIP7 and these signaling events in intestinal epithelial cells remains to be elucidated, ZIP7 may contribute to the maintenance of crypt homeostasis by multiple mechanisms.

\section{Conclusion}

Zinc plays a critical role in the maintenance of intestinal homeostasis by regulating intestinal epithelial cells, host immune cells, and intestinal commensal bacteria. Additionally, recent studies in mice revealed that zinc transporters contribute to regulation of epithelial functions and to the maintenance of intestinal epithelial homeostasis. These findings clarify the self-renewal mechanisms of intestinal epithelial cells as well as the pathogenesis of intestinal diseases. Due to various differences in the features of zinc transporters between mice and humans, the roles of zinc transporters in intestinal epithelial homeostasis and intestinal disease pathogenesis in humans are still undetermined. Further investigations of zinc transporters in humans may advance the understanding of the pathogenesis of gastrointestinal disorders.

\section{Conflicts of Interest}

The authors declare that they have no conflicts of interest. 


\section{Acknowledgments}

This work was supported by grants from the Japan Society for Science (17K09373 and 17H04011) and the Vehicle Racing Commemorative Foundation.

\section{References}

[1] L. W. Peterson and D. Artis, "Intestinal epithelial cells: regulators of barrier function and immune homeostasis," Nature Reviews Cancer, vol. 14, no. 3, pp. 141-153, 2014.

[2] L. G. van der Flier and H. Clevers, "Stem cells, self-renewal, and differentiation in the intestinal epithelium," Annual Review of Physiology, vol. 71, no. 1, pp. 241-260, 2009.

[3] C. Andreini, L. Banci, I. Bertini, and A. Rosato, "Counting the zinc-proteins encoded in the human genome," Journal of Proteome Research, vol. 5, no. 1, pp. 196-201, 2006.

[4] C. Andreini and I. Bertini, "A bioinformatics view of zinc enzymes," Journal of Inorganic Biochemistry, vol. 111, pp. 150-156, 2012.

[5] K. J. Waldron, J. C. Rutherford, D. Ford, and N. J. Robinson, "Metalloproteins and metal sensing," Nature, vol. 460, no. 7257, pp. 823-830, 2009.

[6] C. J. Frederickson, J.-Y. Koh, and A. I. Bush, "The neurobiology of zinc in health and disease," Nature Reviews Neuroscience, vol. 6, no. 6, pp. 449-462, 2005.

[7] M. Murakami and T. Hirano, "Intracellular zinc homeostasis and zinc signaling," Cancer Science, vol. 99, no. 8, pp. 15151522,2008

[8] T. Hirano, M. Murakami, T. Fukada, K. Nishida, S. Yamasaki, and T. Suzuki, "Roles of zinc and zinc signaling in immunity: zinc as an intracellular signaling molecule," Advances in Immunology, vol. 97, pp. 149-176, 2008.

[9] S. L. Sensi, P. Paoletti, A. I. Bush, and I. Sekler, "Zinc in the physiology and pathology of the CNS," Nature Reviews Neuroscience, vol. 10, no. 11, pp. 780-791, 2009.

[10] T. Kambe, T. Tsuji, A. Hashimoto, and N. Itsumura, "The physiological, biochemical, and molecular roles of zinc transporters in zinc homeostasis and metabolism," Physiological Reviews, vol. 95, no. 3, pp. 749-784, 2015.

[11] T. Hara, T.-A. Takeda, T. Takagishi, K. Fukue, T. Kambe, and T. Fukada, "Physiological roles of zinc transporters: molecular and genetic importance in zinc homeostasis," The Journal of Physiological Sciences., vol. 67, no. 2, pp. 283-301, 2017.

[12] T. Fukada and T. Kambe, "Molecular and genetic features of zinc transporters in physiology and pathogenesis," Metallomics, vol. 3, no. 7, pp. 662-674, 2011.

[13] S. Skrovanek, K. DiGuilio, R. Bailey et al., "Zinc and gastrointestinal disease," World Journal of Gastrointestinal Pathophysiology, vol. 5, no. 4, pp. 496-513, 2014.

[14] J. H. van Es, A. Haegebarth, P. Kujala et al., "A critical role for the Wnt effector Tcf4 in adult intestinal homeostatic self-renewal," Molecular and Cellular Biology, vol. 32, no. 10, pp. 1918-1927, 2012.

[15] K. A. Knoop and R. D. Newberry, "Goblet cells: multifaceted players in immunity at mucosal surfaces," Mucosal Immunology, vol. 11, no. 6, pp. 1551-1557, 2018.

[16] J. J. Worthington, F. Reimann, and F. M. Gribble, "Enteroendocrine cells-sensory sentinels of the intestinal environment and orchestrators of mucosal immunity," Mucosal Immunology, vol. 11, no. 1, pp. 3-20, 2018.
[17] H. C. Clevers and C. L. Bevins, "Paneth cells: maestros of the small intestinal crypts," Annual Review of Physiology, vol. 75, no. 1, pp. 289-311, 2013.

[18] A. Sbarbati and F. Osculati, "A new fate for old cells: brush cells and related elements," Journal of Anatomy, vol. 206, no. 4, pp. 349-358, 2005.

[19] H. Miller, J. Zhang, R. Kuolee, G. B. Patel, and W. Chen, "Intestinal M cells: the fallible sentinels?," World Journal of Gastroenterology, vol. 13, no. 10, pp. 1477-1486, 2007.

[20] N. Barker, J. H. van Es, J. Kuipers et al., "Identification of stem cells in small intestine and colon by marker gene Lgr5," Nature, vol. 449, no. 7165, pp. 1003-1007, 2007.

[21] N. Barker, "Adult intestinal stem cells: critical drivers of epithelial homeostasis and regeneration," Nature Reviews Molecular Cell Biology, vol. 15, no. 1, pp. 19-33, 2013.

[22] A. S. Darwich, U. Aslam, D. M. Ashcroft, and A. Rostami-Hodjegan, "Meta-analysis of the turnover of intestinal epithelia in preclinical animal species and humans," Drug Metabolism and Disposition, vol. 42, no. 12, pp. 20162022, 2014.

[23] Ö. H. Yilmaz, P. Katajisto, D. W. Lamming et al., "mTORC1 in the Paneth cell niche couples intestinal stem-cell function to calorie intake," Nature, vol. 486, no. 7404, pp. 490-495, 2012.

[24] W. de Lau, N. Barker, T. Y. Low et al., "Lgr5 homologues associate with Wnt receptors and mediate R-spondin signalling," Nature, vol. 476, no. 7360, pp. 293-297, 2012.

[25] K. S. Carmon, Q. Lin, X. Gong, A. Thomas, and Q. Liu, "LGR5 interacts and cointernalizes with Wnt receptors to modulate Wnt/ $\beta$-catenin signaling," Molecular and Cellular Biology, vol. 32, no. 11, pp. 2054-2064, 2012.

[26] A. Glinka, C. Dolde, N. Kirsch et al., "LGR4 and LGR5 are $\mathrm{R}$-spondin receptors mediating $\mathrm{Wnt} / \beta$-catenin and $\mathrm{Wnt} / \mathrm{PCP}$ signalling," EMBO reports, vol. 12, no. 10, pp. 1055-1061, 2011.

[27] N. Takeda, R. Jain, M. R. LeBoeuf, Q. Wang, M. M. Lu, and J. A. Epstein, "Interconversion between intestinal stem cell populations in distinct niches," Science, vol. 334, no. 6061, pp. 1420-1424, 2011.

[28] H. Tian, B. Biehs, S. Warming et al., "A reserve stem cell population in small intestine renders Lgr5-positive cells dispensable," Nature, vol. 478, no. 7368, pp. 255-259, 2012.

[29] G. C. Hansson, "Role of mucus layers in gut infection and inflammation," Current Opinion in Microbiology, vol. 15, no. 1, pp. 57-62, 2011.

[30] C. Gutzeit, G. Magri, and A. Cerutti, "Intestinal IgA production and its role in host-microbe interaction," Immunological Reviews, vol. 260, no. 1, pp. 76-85, 2014.

[31] M. S. Desai, A. M. Seekatz, N. M. Koropatkin et al., "A dietary fiber-deprived gut microbiota degrades the colonic mucus barrier and enhances pathogen susceptibility," Cell, vol. 167, no. 5, pp. 1339-1353.e21, 2016.

[32] T. Ayabe, D. P. Satchell, C. L. Wilson, W. C. Parks, M. E. Selsted, and A. J. Ouellette, "Secretion of microbicidal alpha-defensins by intestinal Paneth cells in response to bacteria," Nature Immunology, vol. 1, no. 2, pp. 113-118, 2000.

[33] S. Vaishnava, M. Yamamoto, K. M. Severson et al., "The antibacterial lectin RegIIIgamma promotes the spatial segregation of microbiota and host in the intestine," Science, vol. 334, no. 6053, pp. 255-258, 2011.

[34] S. Mukherjee and L. V. Hooper, "Antimicrobial defense of the intestine,” Immunity, vol. 42, no. 1, pp. 28-39, 2015. 
[35] D. Dinsdale, "Ultrastructural localization of zinc and calcium within the granules of rat Paneth cells," Journal of Histochemistry \& Cytochemistry, vol. 32, no. 2, pp. 139$145,1984$.

[36] E. M. Porter, C. L. Bevins, D. Ghosh, and T. Ganz, "The multifaceted Paneth cell," Cellular and Molecular Life Sciences CMLS, vol. 59, no. 1, pp. 156-170, 2002.

[37] K. S. Kobayashi, M. Chamaillard, Y. Ogura et al., "Nod2-dependent regulation of innate and adaptive immunity in the intestinal tract," Science, vol. 307, no. 5710, pp. 731-734, 2005.

[38] L. J. Giblin, C. J. Chang, A. F. Bentley, C. Frederickson, S. J. Lippard, and C. J. Frederickson, "Zinc-secreting Paneth cells studied by ZP fluorescence," Journal of Histochemistry \& Cytochemistry, vol. 54, no. 3, pp. 311-316, 2006.

[39] T. Sato, J. H. van Es, H. J. Snippert et al., "Paneth cells constitute the niche for Lgr5 stem cells in intestinal crypts," Nature, vol. 469, no. 7330, pp. 415-418, 2011.

[40] E. Cario, G. Gerken, and D. K. Podolsky, "Toll-like receptor 2 enhances ZO-1-associated intestinal epithelial barrier integrity via protein kinase C," Gastroenterology, vol. 127, no. 1, pp. 224-238, 2004.

[41] M. H. Zaki, K. L. Boyd, P. Vogel, M. B. Kastan, M. Lamkanfi, and T.-D. Kanneganti, "The NLRP3 inflammasome protects against loss of epithelial integrity and mortality during experimental colitis," Immunity, vol. 32, no. 3, pp. 379-391, 2010.

[42] S. Normand, A. Delanoye-Crespin, A. Bressenot et al., "Nodlike receptor pyrin domain-containing protein 6 (NLRP6) controls epithelial self-renewal and colorectal carcinogenesis upon injury," Proceedings of the National Academy of Sciences of the United States of America, vol. 108, no. 23, pp. 96019606, 2011.

[43] J. R. Turner, "Intestinal mucosal barrier function in health and disease," Nature Reviews Immunology, vol. 9, no. 11, pp. 799-809, 2009.

[44] K. L. Edelblum and J. R. Turner, "The tight junction in inflammatory disease: communication breakdown," Current Opinion in Pharmacology, vol. 9, no. 6, pp. 715-720, 2009.

[45] T. Suzuki, "Regulation of intestinal epithelial permeability by tight junctions," Cellular and Molecular Life Sciences, vol. 70, no. 4, pp. 631-659, 2013.

[46] S. Zeissig, N. Bürgel, D. Günzel et al., "Changes in expression and distribution of claudin 2, 5 and 8 lead to discontinuous tight junctions and barrier dysfunction in active Crohn's disease," Gut, vol. 56, no. 1, pp. 61-72, 2007.

[47] S. Vetrano, M. Rescigno, M. Rosaria Cera et al., "Unique role of junctional adhesion molecule-A in maintaining mucosal homeostasis in inflammatory bowel disease," Gastroenterology, vol. 135, no. 1, pp. 173-184, 2008.

[48] A. Michielan and R. D'Incà, "Intestinal permeability in inflammatory bowel disease: pathogenesis, clinical evaluation, and therapy of leaky gut," Mediators of Inflammation, vol. 2015, Article ID 628157, 10 pages, 2015.

[49] H. Tanaka, M. Takechi, H. Kiyonari, G. Shioi, A. Tamura, and S. Tsukita, "Intestinal deletion of claudin-7 enhances paracellular organic solute flux and initiates colonic inflammation in mice," Gut, vol. 64, no. 10, pp. 1529-1538, 2015.

[50] S. Jäger, E. F. Stange, and J. Wehkamp, "Inflammatory bowel disease: an impaired barrier disease," Langenbeck's Archives of Surgery, vol. 398, no. 1, pp. 1-12, 2013.
[51] J. Wehkamp, M. Koslowski, G. Wang, and E. F. Stange, "Barrier dysfunction due to distinct defensin deficiencies in small intestinal and colonic Crohn's disease," Mucosal Immunology, vol. 1, no. 1, pp. S67-S74, 2008.

[52] J. Wehkamp, N. H. Salzman, E. Porter et al., "Reduced Paneth cell $\alpha$-defensins in ileal Crohn's disease," Proceedings of the National Academy of Sciences of the United States of America, vol. 102, no. 50, pp. 18129-18134, 2005.

[53] L. A. Simms, J. D. Doecke, M. D. Walsh, N. Huang, E. V. Fowler, and G. L. Radford-Smith, "Reduced alpha-defensin expression is associated with inflammation and not NOD2 mutation status in ileal Crohn's disease," Gut, vol. 57, no. 7, pp. 903-910, 2008.

[54] E. Cerrillo, I. Moret, M. Iborra et al., "Alpha-defensins $(\alpha$-Defs) in Crohn's disease: decrease of ileal $\alpha$-Def 5 via permanent methylation and increase in plasma $\alpha$-Def 1-3 concentrations offering biomarker utility," Clinical and Experimental Immunology, vol. 192, no. 1, pp. 120-128, 2018.

[55] D. Takahashi, K. Hase, S. Kimura et al., "The epithelia-specific membrane trafficking factor AP-1B controls gut immune homeostasis in mice," Gastroenterology, vol. 141, no. 2, pp. 621-632, 2011.

[56] D. Boltin, T. T. Perets, A. Vilkin, and Y. Niv, "Mucin function in inflammatory bowel disease: an update," Journal of Clinical Gastroenterology, vol. 47, no. 2, pp. 106-111, 2013.

[57] M. E. V. Johansson, M. Phillipson, J. Petersson, A. Velcich, L. Holm, and G. C. Hansson, "The inner of the two Muc2 mucin-dependent mucus layers in colon is devoid of bacteria," Proceedings of the National Academy of Sciences of the United States of America, vol. 105, no. 39, pp. 15064-15069, 2008.

[58] C. A. Anderson, G. Boucher, C. W. Lees et al., "Meta-analysis identifies 29 additional ulcerative colitis risk loci, increasing the number of confirmed associations to 47," Nature Genetics, vol. 43, no. 3, pp. 246-252, 2011.

[59] A. Franke, D. P. B. McGovern, J. C. Barrett et al., "Genome-wide meta-analysis increases to 71 the number of confirmed Crohn's disease susceptibility loci," Nature Genetics, vol. 42, no. 12, pp. 1118-1125, 2010.

[60] L. Jostins, S. Ripke, K. R. Weersma et al., "Host-microbe interactions have shaped the genetic architecture of inflammatory bowel disease," Nature, vol. 491, no. 7422, pp. 119124, 2012.

[61] J. Z. Liu, S. van Sommeren, H. Huang et al., "Association analyses identify 38 susceptibility loci for inflammatory bowel disease and highlight shared genetic risk across populations," Nature Genetics, vol. 47, no. 9, pp. 979-986, 2015.

[62] H. Clevers and R. Nusse, "Wnt/ $\beta$-catenin signaling and disease," Cell, vol. 149, no. 6, pp. 1192-1205, 2012.

[63] B. Khor, A. Gardet, and R. J. Xavier, "Genetics and pathogenesis of inflammatory bowel disease," Nature, vol. 474, no. 7351, pp. 307-317, 2011.

[64] M. J. Koslowski, Z. Teltschik, J. Beisner et al., “Association of a functional variant in the Wnt co-receptor LRP6 with early onset ileal Crohn's disease," PLoS Genetics, vol. 8, no. 2, article e1002523, 2012.

[65] K. J. Howell, J. Kraiczy, K. M. Nayak et al., "DNA methylation and transcription patterns in intestinal epithelial cells from pediatric patients with inflammatory bowel diseases differentiate disease subtypes and associate with outcome," Gastroenterology, vol. 154, no. 3, pp. 585-598, 2018. 
[66] C. E. Semrad, "Zinc and intestinal function," Current Gastroenterology Reports, vol. 1, no. 5, pp. 398-403, 1999.

[67] A. S. Prasad, "Discovery of human zinc deficiency: its impact on human health and disease," Advances in Nutrition, vol. 4, no. 2, pp. 176-190, 2013.

[68] P. J. Winch, K. E. Gilroy, S. Doumbia et al., "Operational issues and trends associated with the pilot introduction of zinc for childhood diarrhoea in Bougouni district, Mali," Journal of Health, Population and Nutrition, vol. 26, no. 2, pp. 151-162, 2008.

[69] M. Lazzerini and H. Wanzira, "Oral zinc for treating diarrhoea in children," Cochrane Systematic Review, vol. 12, no. 1, article CD005436, 2016.

[70] C. L. F. Walker and R. E. Black, "Zinc for the treatment of diarrhoea: effect on diarrhoea morbidity, mortality and incidence of future episodes," International Journal of Epidemiology, vol. 39, Supplement 1, pp. i63-i69, 2010.

[71] A. H. Shankar and A. S. PRASAD, "Zinc and immune function: the biological basis of altered resistance to infection," The American Journal of Clinical Nutrition, vol. 68, no. 2, Supplement 2, pp. 447S-463S, 1998.

[72] J. Z. Liu, S. Jellbauer, A. J. Poe et al., "Zinc sequestration by the neutrophil protein calprotectin enhances Salmonella growth in the inflamed gut," Cell Host \& Microbe., vol. 11, no. 3, pp. 227-239, 2012.

[73] A. N. Alam, S. A. Sarker, M. A. Wahed, M. Khatun, and M. M. Rahaman, "Enteric protein loss and intestinal permeability changes in children during acute shigellosis and after recovery: effect of zinc supplementation," Gut, vol. 35, no. 12, pp. 1707-1711, 1994.

[74] S. K. Roy, R. Raqib, W. Khatun et al., "Zinc supplementation in the management of shigellosis in malnourished children in Bangladesh," European Journal of Clinical Nutrition, vol. 62, no. 7, pp. 849-855, 2008.

[75] R. Raqib, S. K. Roy, M. J. Rahman et al., "Effect of zinc supplementation on immune and inflammatory responses in pediatric patients with shigellosis," The American Journal of Clinical Nutrition, vol. 79, no. 3, pp. 444-450, 2004.

[76] M. J. Rahman, P. Sarker, S. K. Roy et al., "Effects of zinc supplementation as adjunct therapy on the systemic immune responses in shigellosis," The American Journal of Clinical Nutrition, vol. 81, no. 2, pp. 495-502, 2005.

[77] S. K. Sikora, D. Spady, C. Prosser, and W. El-Matary, "Trace elements and vitamins at diagnosis in pediatric-onset inflammatory bowel disease," Clinical Pediatrics, vol. 50, no. 6, pp. 488-492, 2011.

[78] D. Owczarek, "Diet and nutritional factors in inflammatory bowel diseases," World Journal of Gastroenterology, vol. 22, no. 3, pp. 895-905, 2016.

[79] G. C. Sturniolo, V. Di Leo, A. Ferronato, A. D'Odorico, and R. D'Incà, "Zinc supplementation tightens "leaky gut" in Crohn's disease," Inflammatory Bowel Diseases, vol. 7, no. 2, pp. 94-98, 2001.

[80] S. Siva, D. T. Rubin, G. Gulotta, K. Wroblewski, and J. Pekow, "Zinc deficiency is associated with poor clinical outcomes in patients with inflammatory bowel disease," Inflammatory Bowel Diseases, vol. 23, no. 1, pp. 152-157, 2017.

[81] A. N. Ananthakrishnan, H. Khalili, M. Song, L. M. Higuchi, J. M. Richter, and A. T. Chan, "Zinc intake and risk of Crohn's disease and ulcerative colitis: a prospective cohort study," International Journal of Epidemiology, vol. 44, no. 6, pp. 1995-2005, 2015.

[82] H. Iwaya, M. Kashiwaya, A. Shinoki et al., "Marginal zinc deficiency exacerbates experimental colitis induced by dextran sulfate sodium in rats," The Journal of Nutrition, vol. 141, no. 6, pp. 1077-1082, 2011.

[83] E. Suwendi, H. Iwaya, J.-S. Lee, H. Hara, and S. Ishizuka, "Zinc deficiency induces dysregulation of cytokine productions in an experimental colitis of rats," Biomedical Research, vol. 33, no. 6, pp. 329-336, 2012.

[84] J. Li, H. Chen, B. Wang et al., " $\mathrm{ZnO}$ nanoparticles act as supportive therapy in DSS-induced ulcerative colitis in mice by maintaining gut homeostasis and activating Nrf2 signaling," Scientific Reports, vol. 7, article 43126, no. 1, 2017.

[85] C. D. Tran, J. M. Ball, S. Sundar, P. Coyle, and G. S. Howarth, "The role of zinc and metallothionein in the dextran sulfate sodium-induced colitis mouse model," Digestive Diseases and Sciences, vol. 52, no. 9, pp. 2113-2121, 2007.

[86] G. C. Sturniolo, W. Fries, E. Mazzon, V. Di Leo, M. Barollo, and R. D'Incà, "Effect of zinc supplementation on intestinal permeability in experimental colitis," The Journal of Laboratory and Clinical Medicine, vol. 139, no. 5, pp. 311-315, 2002.

[87] J.-S. Park, J. Choi, J. Y. Kwon et al., "A probiotic complex, rosavin, zinc, and prebiotics ameliorate intestinal inflammation in an acute colitis mouse model," Journal of Translational Medicine, vol. 16, no. 1, p. 37, 2018.

[88] P. Popovics and A. J. Stewart, "GPR39: a $\mathrm{Zn}^{2+}$-activated G protein-coupled receptor that regulates pancreatic, gastrointestinal and neuronal functions," Cellular and Molecular Life Sciences, vol. 68, no. 1, pp. 85-95, 2011.

[89] M. Hershfinkel, "The zinc sensing receptor, ZnR/GPR39, in health and disease," International Journal of Molecular Sciences, vol. 19, no. 2, p. 439, 2018.

[90] L. Sunuwar, M. Medini, L. Cohen, I. Sekler, and M. Hershfinkel, "The zinc sensing receptor, ZnR/GPR39, triggers metabotropic calcium signalling in colonocytes and regulates occludin recovery in experimental colitis," Philosophical Transactions of the Royal Society B: Biological Sciences, vol. 371, no. 1700, 2016.

[91] N. A. Hering, M. Fromm, and J.-D. Schulzke, "Determinants of colonic barrier function in inflammatory bowel disease and potential therapeutics," Journal of Physiology, vol. 590, no. 5, pp. 1035-1044, 2012.

[92] B. Zhang and Y. Guo, "Supplemental zinc reduced intestinal permeability by enhancing occludin and zonula occludens protein-1 (ZO-1) expression in weaning piglets," British Journal of Nutrition, vol. 102, no. 5, pp. 687-693, 2009.

[93] A. Finamore, M. Massimi, L. Conti Devirgiliis, and E. Mengheri, "Zinc deficiency induces membrane barrier damage and increases neutrophil transmigration in Caco-2 cells," The Journal of Nutrition, vol. 138, no. 9, pp. 16641670, 2008.

[94] Y. Miyoshi, S. Tanabe, and T. Suzuki, "Cellular zinc is required for intestinal epithelial barrier maintenance via the regulation of claudin-3 and occludin expression," American Journal of Physiology-Gastrointestinal and Liver Physiology, vol. 311, no. 1, pp. G105-G116, 2016.

[95] S. Wiegand, S. S. Zakrzewski, M. Eichner et al., "Zinc treatment is efficient against Escherichia coli $\alpha$-haemolysin-induced intestinal leakage in mice," Scientific Reports, vol. 7, article 45649, no. 1, 2017. 
[96] X. Wang, M. C. Valenzano, J. M. Mercado, E. P. Zurbach, and J. M. Mullin, "Zinc supplementation modifies tight junctions and alters barrier function of CACO-2 human intestinal epithelial layers," Digestive Diseases and Sciences, vol. 58, no. 1, pp. 77-87, 2013.

[97] Y. Shao, P. G. Wolf, S. Guo, Y. Guo, H. R. Gaskins, and B. Zhang, "Zinc enhances intestinal epithelial barrier function through the PI3K/AKT/mTOR signaling pathway in Caco-2 cells," The Journal of Nutritional Biochemistry, vol. 43, pp. 18-26, 2017.

[98] L. Cohen, I. Sekler, and M. Hershfinkel, "The zinc sensing receptor, ZnR/GPR39, controls proliferation and differentiation of colonocytes and thereby tight junction formation in the colon," Cell Death and Differentiation, vol. 5, no. 6, pp. e1307-e1312, 2014.

[99] G. J. Guthrie, T. B. Aydemir, C. Troche, A. B. Martin, S.-M. Chang, and R. J. Cousins, "Influence of ZIP14 (slc39A14) on intestinal zinc processing and barrier function," American Journal of Physiology-Gastrointestinal and Liver Physiology, vol. 308, no. 3, pp. G171-G178, 2015.

[100] T. Joeris, K. Müller-Luda, W. W. Agace, and A. M. Mowat, "Diversity and functions of intestinal mononuclear phagocytes," Mucosal Immunology, vol. 10, no. 4, pp. 845-864, 2017.

[101] A. Lahiri and C. Abraham, "Activation of pattern recognition receptors up-regulates metallothioneins, thereby increasing intracellular accumulation of zinc, autophagy, and bacterial clearance by macrophages," Gastroenterology, vol. 147, no. 4, pp. 835-846, 2014.

[102] C. Casén, H. C. Vebø, M. Sekelja et al., "Deviations in human gut microbiota: a novel diagnostic test for determining dysbiosis in patients with IBS or IBD," Alimentary Pharmacology \& Therapeutics, vol. 42, no. 1, pp. 71-83, 2015.

[103] J. P. Zackular, J. L. Moore, A. T. Jordan et al., "Dietary zinc alters the microbiota and decreases resistance to Clostridium difficile infection," Nature Medicine, vol. 22, no. 11, pp. 13301334, 2016.

[104] D. Li, J.-P. Achkar, T. Haritunians et al., "A pleiotropic missense variant in SLC39A8 is associated with Crohn's disease and human gut microbiome composition," Gastroenterology, vol. 151, no. 4, pp. 724-732, 2016.

[105] J. Dufner-Beattie, F. Wang, Y. M. Kuo, J. Gitschier, D. Eide, and G. K. Andrews, "The acrodermatitis enteropathica gene ZIP4 encodes a tissue-specific, zinc-regulated zinc transporter in mice," The Journal of Biological Chemistry, vol. 278, no. 35, pp. 33474-33481, 2003.

[106] J. Dufner-Beattie, Y.-M. Kuo, J. Gitschier, and G. K. Andrews, "The adaptive response to dietary zinc in mice involves the differential cellular localization and zinc regulation of the zinc transporters ZIP4 and ZIP5," The Journal of Biological Chemistry, vol. 279, no. 47, pp. 4908249090, 2004.

[107] T. Kambe and G. K. Andrews, "Novel proteolytic processing of the ectodomain of the zinc transporter ZIP4 (SLC39A4) during zinc deficiency is inhibited by acrodermatitis enteropathica mutations," Molecular and Cellular Biology, vol. 29, no. 1, pp. 129-139, 2009.

[108] B. P. Weaver, J. Dufner-Beattie, T. Kambe, and G. K. Andrews, "Novel zinc-responsive post-transcriptional mechanisms reciprocally regulate expression of the mouse Slc39a4 and Slc39a5 zinc transporters (Zip4 and Zip5)," Biological Chemistry, vol. 388, no. 12, pp. 1301-1312, 2007.
[109] K. Wang, B. Zhou, Y.-M. Kuo, J. Zemansky, and J. Gitschier, "A novel member of a zinc transporter family is defective in acrodermatitis enteropathica," American Journal of Human Genetics, vol. 71, no. 1, pp. 66-73, 2002.

[110] S. Schmitt, S. Küry, M. Giraud, B. Dréno, M. Kharfi, and S. Bézieau, "An update on mutations of the SLC39A4 gene in acrodermatitis enteropathica," Human Mutation, vol. 30, no. 6, pp. 926-933, 2009.

[111] S. Küry, B. Dréno, S. Bézieau et al., "Identification of SLC39A4, a gene involved in acrodermatitis enteropathica," Nature Genetics., vol. 31, no. 3, pp. 239-240, 2002.

[112] R. J. McMahon and R. J. Cousins, "Regulation of the zinc transporter ZnT-1 by dietary zinc," Proceedings of the National Academy of Sciences of the United States of America, vol. 95, no. 9, pp. 4841-4846, 1998.

[113] J. P. Liuzzi, R. K. Blanchard, and R. J. Cousins, "Differential regulation of zinc transporter 1,2, and 4 mRNA expression by dietary zinc in rats," The Journal of Nutrition, vol. 131, no. 1, pp. 46-52, 2001.

[114] Z. L. Huang, J. Dufner-Beattie, and G. K. Andrews, "Expression and regulation of SLC39A family zinc transporters in the developing mouse intestine," Developmental Biology, vol. 295, no. 2, pp. 571-579, 2006.

[115] J. Geiser, R. C. De Lisle, and G. K. Andrews, "The zinc transporter Zip5 (Slc39a5) regulates intestinal zinc excretion and protects the pancreas against zinc toxicity," PLoS One, vol. 8, no. 11, article e82149, 2013.

[116] K. A. Jackson, R. M. Helston, J. A. McKay, E. D. O'Neill, J. C. Mathers, and D. Ford, "Splice variants of the human zinc transporter ZnT5 (SLC30A5) are differentially localized and regulated by zinc through transcription and mRNA stability," Journal of Biological Chemistry, vol. 282, no. 14, pp. $10423-$ 10431, 2007.

[117] R. A. Valentine, K. A. Jackson, G. R. Christie, J. C. Mathers, P. M. Taylor, and D. Ford, "ZnT5 variant B is a bidirectional zinc transporter and mediates zinc uptake in human intestinal Caco-2 cells," The Journal of Biological Chemistry, vol. 282, no. 19, pp. 1438914393, 2007.

[118] G. Vela, P. Stark, M. Socha, A. K. Sauer, S. Hagmeyer, and A. M. Grabrucker, "Zinc in gut-brain interaction in autism and neurological disorders," Neural Plasticity, vol. 2015, Article ID 972791, 15 pages, 2015.

[119] J. Geiser, K. J. T. Venken, R. C. De Lisle, and G. K. Andrews, "A mouse model of acrodermatitis enteropathica: loss of intestine zinc transporter ZIP4 (Slc39a4) disrupts the stem cell niche and intestine integrity," PLoS Genetics, vol. 8, no. 6, article e1002766, 2012.

[120] A. B. Podany, J. Wright, R. Lamendella, D. I. Soybel, and S. L. Kelleher, "ZnT2-mediated zinc import into Paneth cell granules is necessary for coordinated secretion and Paneth cell function in mice," Cellular and Molecular Gastroenterology and Hepatology, vol. 2, no. 3, pp. 369-383, 2016.

[121] W. Ohashi, S. Kimura, T. Iwanaga et al., "Zinc transporter SLC39A7/ZIP7 promotes intestinal epithelial self-renewal by resolving ER stress," PLoS Genetics, vol. 12, no. 10, article e1006349, 2016.

[122] H. Gehart and H. Clevers, "Tales from the crypt: new insights into intestinal stem cells," Nature Reviews Gastroenterology \& Hepatology, vol. 16, no. 1, pp. 19-34, 2018. 
[123] K. M. Taylor, S. Hiscox, R. I. Nicholson, C. Hogstrand, and P. Kille, "Protein kinase CK2 triggers cytosolic zinc signaling pathways by phosphorylation of zinc channel ZIP7," Science Signaling, vol. 5, no. 210, article ra11, 2012.

[124] E. Nolin, S. Gans, L. Llamas et al., "Discovery of a ZIP7 inhibitor from a Notch pathway screen," Nature Chemical Biology, vol. 15, no. 2, pp. 179-188, 2019. 


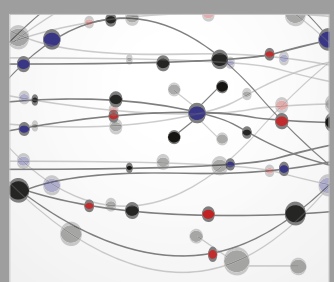

The Scientific World Journal
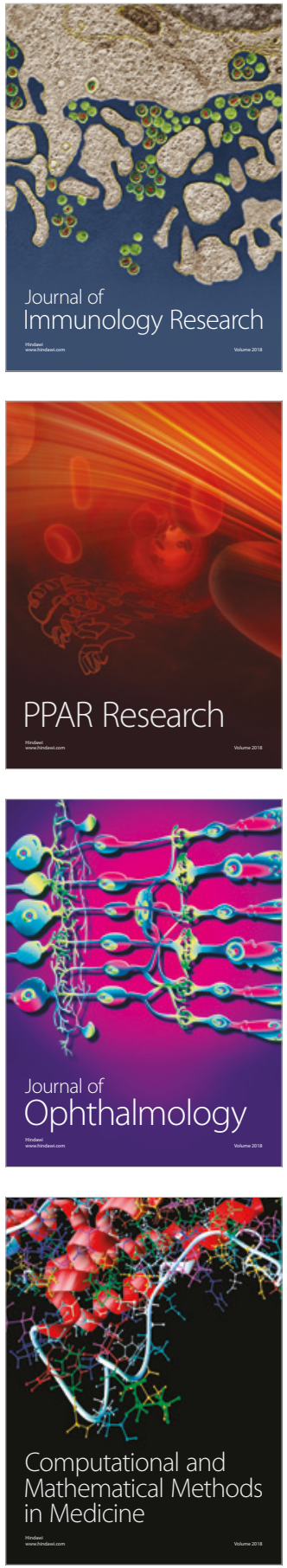

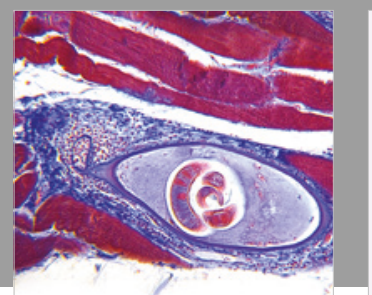

Gastroenterology Research and Practice

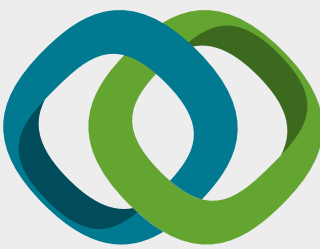

\section{Hindawi}

Submit your manuscripts at

www.hindawi.com
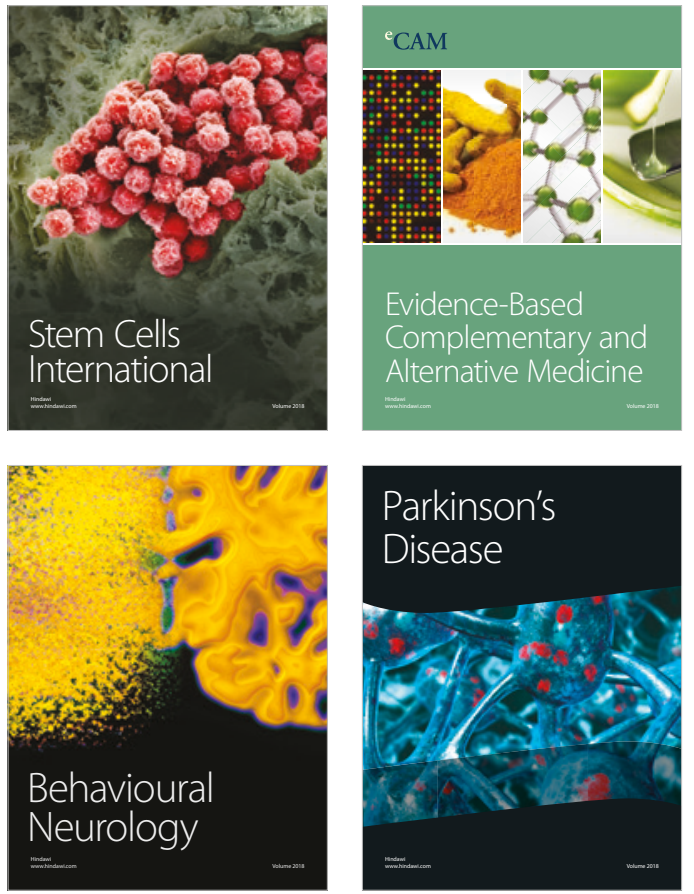

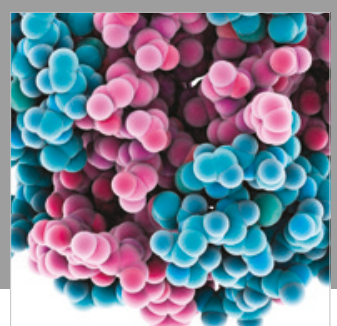

ournal of

Diabetes Research

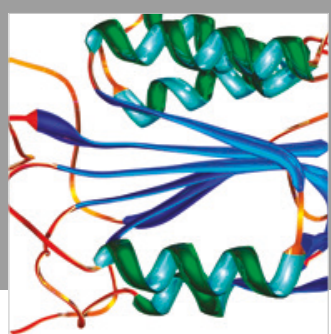

Disease Markers
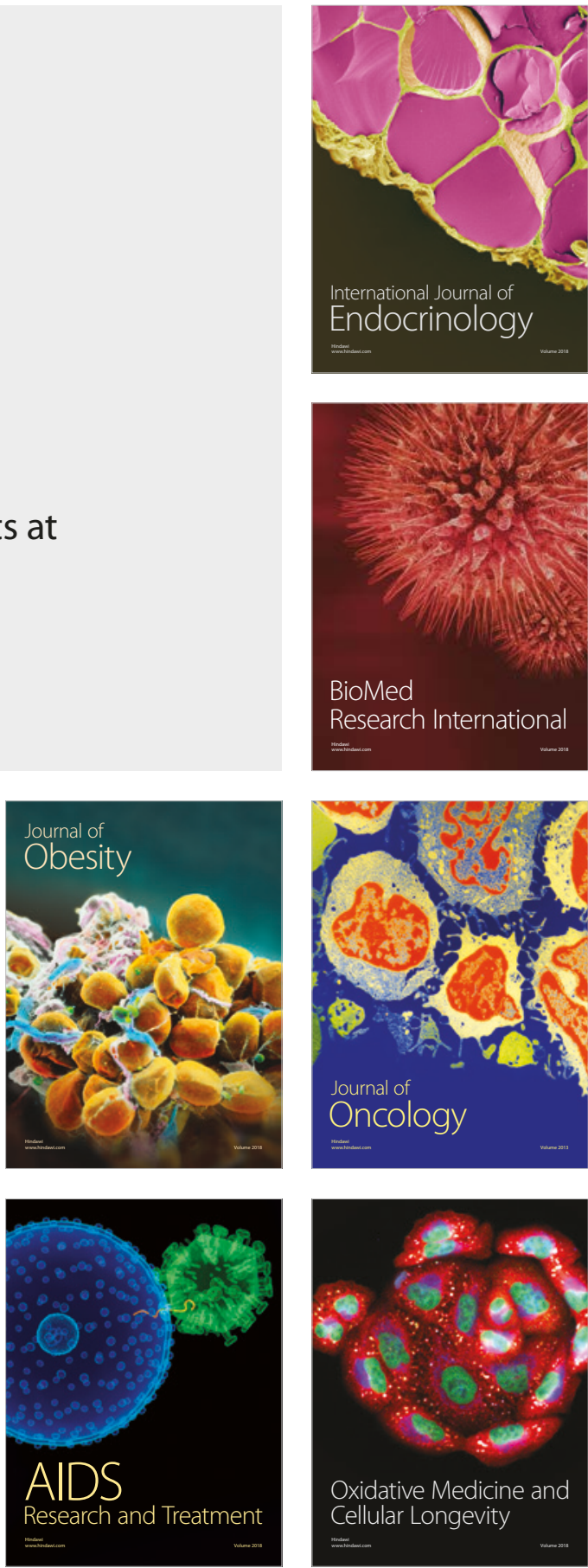